\title{
Structural Violence and Pakistan's Health Situation
}

\author{
Muhammad Ahmed Abdullah \\ Assistant Professor, Community Medicine, Islamabad Medical and Dental College
}

Structural violence was first defined by Johan Galtung as "A form of violence wherein some social structure or social institution may harm people by preventing them from meeting their basic needs"1 The concept has been studied extensively over the years and is considered as a major reason for strangled development in various resource limited settings around the world. The idea of structural violence implies that people in power fail to provide essential services for the people they are responsible for; this failure can be intentional or unintentional, nevertheless long-term effects influence the marginalized population adversely. ${ }^{2}$

Pakistan is no stranger to structural violence; which is evident from the persistently deteriorating human development indicators of the country. Despite being the sixth most populous country in the world, a nuclear armed state, and a resource rich agricultural land, the health situation has gone from bad to worse. According to the Pakistan Demographic Health survey 2017-18, the neonatal mortality of the country is 42 per 1000 live births, the infant mortality rate is 62 per 1000 and the under 5 mortality rate is 74 per $1000 .{ }^{3}$ Lack of effective health services, underutilized primary and secondary level healthcare delivery systems, an overburdened tertiary care system and a reactive rather than a proactive approach towards the health needs of the people are just some of the reasons for the dismal state of affairs. Pakistan's political terrain has been uneven and fluctuant, yet no politico-social variations have been able to halt the constant deterioration in the health circumstances. ${ }^{4}$

Pakistan is a triple disease burden country where infectious diseases, non-communicable diseases and accidents/violence all have their due share in the

\section{Correspondence:}

Muhammad Ahmed Abdullah

Email:drahmedabdullah83@gmail.com morbidity and mortality. ${ }^{5}$ One major point to consider here is the trivial proportion of our GDP spent on health. According to the Economic Survey of Pakistan for the financial year $2017-18$, only $0.49 \%$ of the GDP was spent on health. This meager amount is no surprise because the highest ever percentage was $0.77 \%$ of the GDP in 2015-16. ${ }^{6}$ These figures when viewed through the lens of human behaviors, are magnified in the form of the government's intent for improving the health of the people. Most expenditure on health is out of pocket and is spent in the thriving private health care sector of the country. Mentioning the idea of the poverty disease cycle, at this point is also imperative, as diseases have dire consequences not only on the health but also the financial circumstances of people. ${ }^{7}$

In the larger scheme of things, a health systems-based approach is the need of the hour, which has a proactive instead of a reactive outlook. In the current case scenario, the health system fails to solve problems that have been complicated by lack of awareness of the people and limited service delivery structure; this in turn further extrapolates the burden on the already crumbling health systems of the country. A robust leadership and governance model are probably the most needed rung in the ladder of health improvement and promotion in the country. ${ }^{8}$

\section{References}

1. Galtung J, Höivik T. Structural and direct violence: A note on operationalization. JPR. 1971; 8(1):73-6

2. Rotberg RI. The new nature of nation-state failure. Washington quarterly. 2002;25(3):83-96

3. National Institute of Population Studies, Pakistan. Pakistan Demographic Health Survey (PDHS) 201718 
4. Nizar H, Chagani P. Analysis of health care delivery system in Pakistan and Singapore. Int J Nurs Stud. 2016; 8(2).

5. Hyder AA, Morrow RH. Applying burden of disease methods in developing countries: a case study from Pakistan. Am J Public Health. 2000; 90(8):1235

6. Ministry of Finance, Pakistan. Economic Survey of Pakistan 2017-18.
7. Abdullah MA, Basharat Z, Lodhi O, Wazir MH, Khan HT, Sattar NY, Zahid A. A qualitative exploration of Pakistan's street children, as a consequence of the poverty-disease cycle. Infectious diseases of poverty. 2014; 3(1):11

8. Shaikh BT. Health systems research in Pakistan: issues, challenges and way forward. J Ayub Med Coll Abbottabad.

2015;

27(2):257-8. 